\title{
Weighing the Pros and Cons: Transformation of Angle of View for Three Gorges Dam
}

\author{
Wei Zhang1,2 \\ ${ }^{1}$ Mining \& Mineral Resources Division, Department of Business Administration, Chinalco China Copper \\ Corporation Limited, Beijing, China \\ ${ }^{2}$ Department of Mining and Materials Engineering, McGill University, Montreal, Canada \\ Email: zhang wei@chalco.com.cn
}

Received 16 October 2014; revised 18 November 2014; accepted 29 November 2014

Copyright (C) 2014 by author and Scientific Research Publishing Inc.

This work is licensed under the Creative Commons Attribution International License (CC BY).

http://creativecommons.org/licenses/by/4.0/

c) (i) Open Access

\begin{abstract}
Three Gorges Dam Project is the world's largest water-control and hydraulic-electric project in the $21^{\text {st }}$ century. However, it has been shrouded in controversy since long even before it began construction in 1994. On one hand, the benefits of the Three Gorges Dam are flood control, power generation, navigation, aquaculture, tourism, ecological protection, environmental purification, development-oriented resettlement, transfer of water from southern China to northern China, and water supply and irrigation. On the other hand, the drawbacks of the dam are environmental impact, effect on local culture and aesthetic values, and sedimentation. In an environmental impact point of view, the Three Gorges Dam shows evidence that it has more advantages than disadvantages. Thus, by carefully balancing the pros and cons, one can say that the Three Gorges Dam is an environmentally feasible project.
\end{abstract}

\section{Keywords}

Environmental Impact, Flood Control, Power Generation, Ecological Protection

\section{Introduction}

The $3^{\text {rd }}$ of April, 1992 saw the passing of "The Resolution for the Construction of the Three Gorges Project (TGP)” on the Yangtze river at the $5^{\text {th }}$ session of the $7^{\text {th }}$ National People's Congress at the dignified People's Great Hall in the capital city Beijing [1]. It was this resolution that terminated the 75-year-old debate on the construction of the Three Gorges Dam. In fact, numerous politicians, scientists, and engineers have fought for many 
years for the realization of the TGP. Unfortunately, they have devoted their whole lives to it, and have departed the world with eternal regret leaving the long-cherished dream unrealized. Today, their dream has become true.

The Three Gorges Dam (Figure 1) is a Chinese hydroelectric river dam located in Sandouping, Yichang, Hubei, China. It spans the Yangtze river and has a total electric generating capacity of approximately 22,500 megawatts [2]. The Three Gorges Dam is the largest hydroelectric power station in the world by capacity. Since the Great Wall, the Three Gorges Project is the biggest project that has been undertaken in China for years. The Three Gorges Dam is estimated to be fully operational in 2011 [3]. One of the main reasons for the construction of the Three Gorges Dam is that it will act as a clean alternative to coal-fired power stations. Current widespread power shortages caused by bad weather and coal shortages are underscoring China's need for more electricity to fuel its fast-growing economy [4].

As with all technological implementations, there are advantages and disadvantages. This paper focuses mainly on the benefits and the drawbacks of the Three Gorges Dam, with specific emphasis on environmental impacts.

\section{Ushering towards a New Era}

The Yangtze river, rising in the glaciers and snow-covered mountains of the Qinghai-Tibetan Plateau, and fed by hundreds of tributaries, wanders eastward across the mainland of China [5]. It makes an incessant rush into the East China Sea. The enormous hydroelectric resources of the Yangtze, producing no waste gases, no waste water or waste residues, are superior to oilfields and coalfields in terms of energy generating capacity [6]. Hence, the Three Gorges Dam is therefore considered as the "King" of all energies in China.

From its start to its end, the Yangtze river spans over 6300 kilometers. Its annual runoff into the sea amounts to nearly 1000 billion $\mathrm{m}^{3}$ and its total drop is more than 5800 meters with a hydroelectric power potential of up to a maximum of 268 million kilowatts [1]. In order to harness the Yangtze river and to develop its resources, extensive efforts in survey, planning, and scientific research have been done. After overall planning, repeated studies and verifications, a conclusion has been made: the TGP is the key to the flood control and exploitation of the resources of the river [7].

The TGP, which is attracting worldwide attention today, is located at Sandouping, Yichang, Hubei Province in the middle section of Xiling Gorge, about $38 \mathrm{~km}$ upstream of the Gezhouba Project (another dam for flood control) [8]. The dam site boasts excellent natural conditions such as a relatively wide valley, sound and intact granite bedrock, an average annual runoff of about 500 billion $\mathrm{m}^{3}$, and a vast drainage basin of more than 1 million $\mathrm{km}^{2}$ [3]. Decades of investigations and studies resulted in the final approval of Sandouping to be the site of the TGP.

It was during the $5^{\text {th }}$ session of the $7^{\text {th }}$ National People's Congress that the examination and debate on the feasibility of the TGP came to an end, and a new era to harness and to develop the Yangtze river was ushered in Figure 2 shows the unfinished building of the Three Gorges Dam.

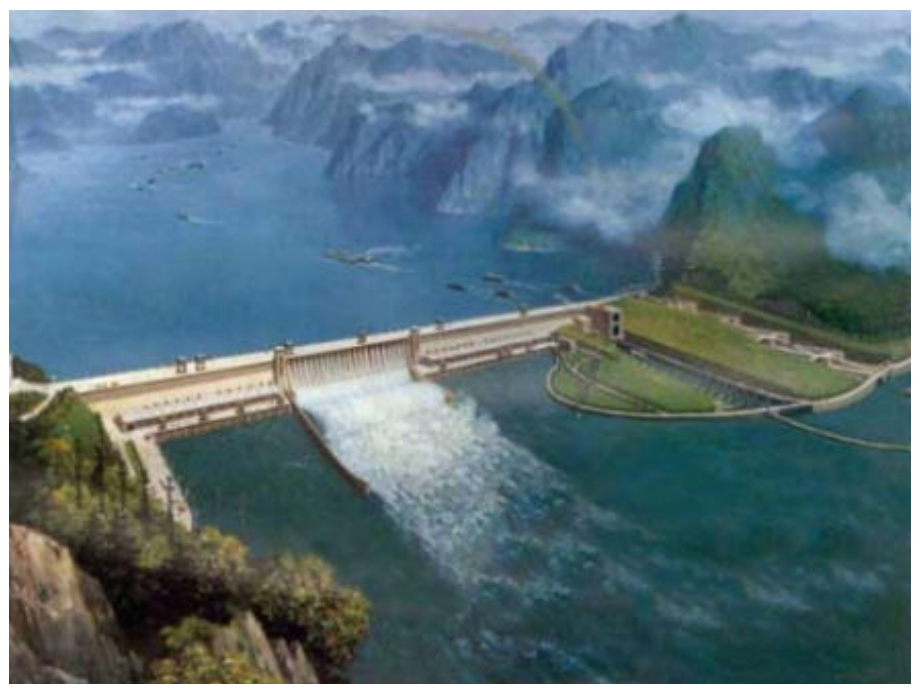

Figure 1. Schematic of the Three Gorges Dam. 


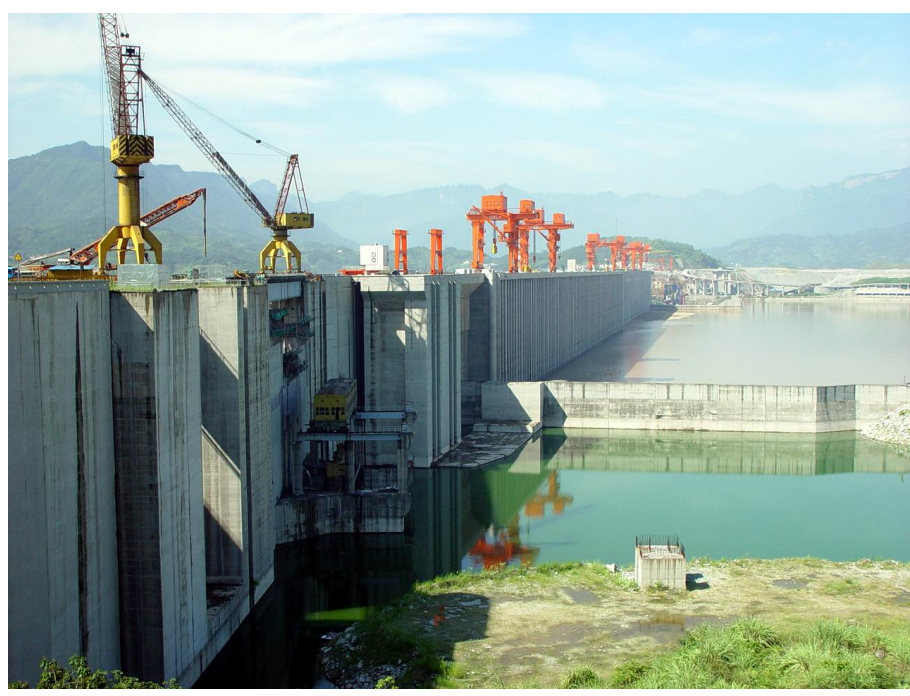

Figure 2. The unfinished building of Three Gorges Dam.

\section{The Magnificent Yangtze Three Gorges Project}

The concrete gravity Three Gorges Dam is $3035 \mathrm{~m}$ long on the top, with the crest at $185 \mathrm{~m}$ high. The designed normal pool level of the reservoir is $175 \mathrm{~m}$ high, and the total storage capacity is 39.3 billion $\mathrm{m}^{3}$, of which 22.15 billion $\mathrm{m}^{3}$ is for flood control [7]. The silt flushing bays are to be arranged in the concrete gravity dam and at the bottom of the power station, with a silt flushing capacity of $2460 \mathrm{~m}^{3}$ per second. The discharging capacity of the spillway which constitutes the middle section of the dam is $110,000 \mathrm{~m}^{3}$ per second. The two designed powerhouses to be located on both sides of the spillway have 26 units of generators of 700,000 kW each, with a total capacity of 18.2 million $\mathrm{kW}$ [8]. The designed one-way shipping capacity of the navigation facilities (including a twin 5-flight shiplock and a one-step vertical shiplift) is 50 million tons a year. The shiplock can adequately handle tows up to 10,000 tons and the shiplift can provide immediate service for any vessels under 3000 tons [2].

The following list shows important numbers related to the construction of the Three Gorges Dam [9]:

Excavation: 102,600,000 $\mathrm{m}^{3}$

Fill: 29,300,000 $\mathrm{m}^{3}$

Concrete: $27,150,000 \mathrm{~m}^{3}$

Metals: 281,000 tons

The estimated total static investment of the TGP is 95.46 billion yuan (US $\$ 10.97$ billion) based on the price level of 1993, 50.09 billion yuan (US\$5.75 billion) of which is for project construction, 30.07 billion yuan (US\$3.45 billion) for resettlement, and 15.3 billion yuan (US\$1.75 billion) for the power transmission [2]. Upon completion, the Three Gorges Dam will be beneficial in ten aspects, which will be discussed in the next section.

\section{The Ten Major Benefits of the Three Gorges Dam}

The TGP is a multi-purpose project which offers many enormous benefits such as flood control, power generation, navigation, aquaculture, tourism, ecological protection, environmental purification, development-oriented resettlement, transfer of water from southern China to northern China, and water supply and irrigation.

\subsection{Flood Control}

The plain areas along the middle and lower reaches of the Yangtze boast highly developed industries and agricultural lands. Nevertheless, these areas are most vulnerable to floods, because the flood level can be 6 to 17 meters higher than the ground level of the adjacent plains and they are protected only by the 33,000 km long dykes. Flooding has been very frequent since ancient times and the reoccurrence interval is about 10 years. This reoccurrence is due to the flood-discharging capacity of the river channel from Jingjiang to Wuhan, which is only 60,000 to $70,000 \mathrm{~m}^{3} / \mathrm{s}$. This is far too small to discharge the large floods as high as $110,000 \mathrm{~m}^{3} / \mathrm{s}$ [9]. The 
Three Gorges Dam can protect the downstream plains against the biggest flood and prevent devastating disasters from occurring with the help of the flood diversion structure. The Three Gorges Dam will ensure the safety of human lives and properties of more than 15 million people inhabiting the downstream areas (1.53 million hectares farmland), as well as the Beijing-Guangzhou and Beijing-Jiulong railroads [10]. Figure 3 shows a top view of the flood control by the Three Gorges Dam.

\subsection{Power Generation}

The total annual output of the two stations (Three Gorges power station and Gezhouba power station) is expected to reach 105 billion $\mathrm{kWh}$. The power output will generate a yearly net value of 10.5 billion yuan (US\$1.2 billion) based on the assumption that the price of electricity is 0.1 yuan (US\$0.0114) per kWh, and an output value of 525 billion yuan (US\$60.3 billion) based on the assumption that $1 \mathrm{kWh}$ of electricity can produce an output value of 5 yuan (US\$0.57), which can result in job opportunities for nearly 5.25 million people assuming that each working person can generate an annual revenue of 10,000 yuan (US\$1149) [11]. It is interesting to note that the Three Gorges Dam's site enjoys a very advantageous geographical position, being within $1000 \mathrm{~km}$ of many industrial centers. It is expected to be the network junction for all the power grids in the country [3]. When the grid goes into operation, it will not only supplement the available thermal power, hydropower, and nuclear power in the country, but also upgrade the quality and efficiency of the grid, which will certainly make the TGP the national electricity dispatching centre.

\subsection{Navigation}

The completion of the TGP will substantially improve the navigation conditions on the river above the dam, with the navigation channel broadened to an average of 1100 meters, enabling 10,000 tons tows to sail all the way from Shanghai to Chongqing. This improvement can lead to an annual increase in one-way shipping capacity to 50 million tons (compared to 10 million tons prior to the existence of the Three Gorges Dam) and a cut in the shipping cost by $37 \%$, creating conditions capable of boosting the economy of the Southwest, Central, and Eastern China [8].

\subsection{Aquaculture}

The 175 meters high dam will lead to the formation of a huge reservoir of $1150 \mathrm{~km}^{2}$. Apart from the waterway, there is $700 \mathrm{~km}^{2}$ of remaining water surface. The flow velocity of the latter water will be slower. In addition, the water will be clearer, more nutritious, and warmer in the surface layer. Hence, this water will make a vast fresh water aquaculture base for raising shrimps, shellfish, fishes, geese, ducks, and crabs. Consequently, the formation of the reservoir will result in rapid development of agriculture, forestry, animal husbandry, as well as fishery [12].

\subsection{Tourism}

Upon completion of the TGP, the water level behind the dam will be raised by 110 meters. Although some scenic spots and places of historical interests such as Qu Yuan Temple, Zhang Fei Temple, and several sites of stone inscription will be submerged, the scenery on the Three Gorges Dam will remain magnificent and unique. Note that careful plans have been made to remove or rebuild the submerged historical structures [10]. Also, the formation of the artificial lake among spectacular mountains will only add to the beauty of the Three Gorges Dam since many new scenic spots will turn up and dozens of scenic spots scattered along the Three Gorges Dam will become easily accessible. These include the Dazu Stone Sculpture, the Gaolan scenic area covered with an ocean of pine trees, the Minor Three Gorges along the Daning river, etc. [8]. It is without doubt that the Three Gorges Dam, with a combination of natural beauty, ancient cultural relics and historical sites, will attract travelers from around the world (Figure 4).

\subsection{Ecological Protection}

The Three Gorges Dam's reservoir may change the climate of the surrounding areas. In fact, the temperature during summer and winter may drop and rise by about $2^{\circ} \mathrm{C}$ respectively. Amazingly, this climate change is favorable to the growth of tung trees, orange trees, chestnut trees, mulberry trees, and tea plants, which all need a 


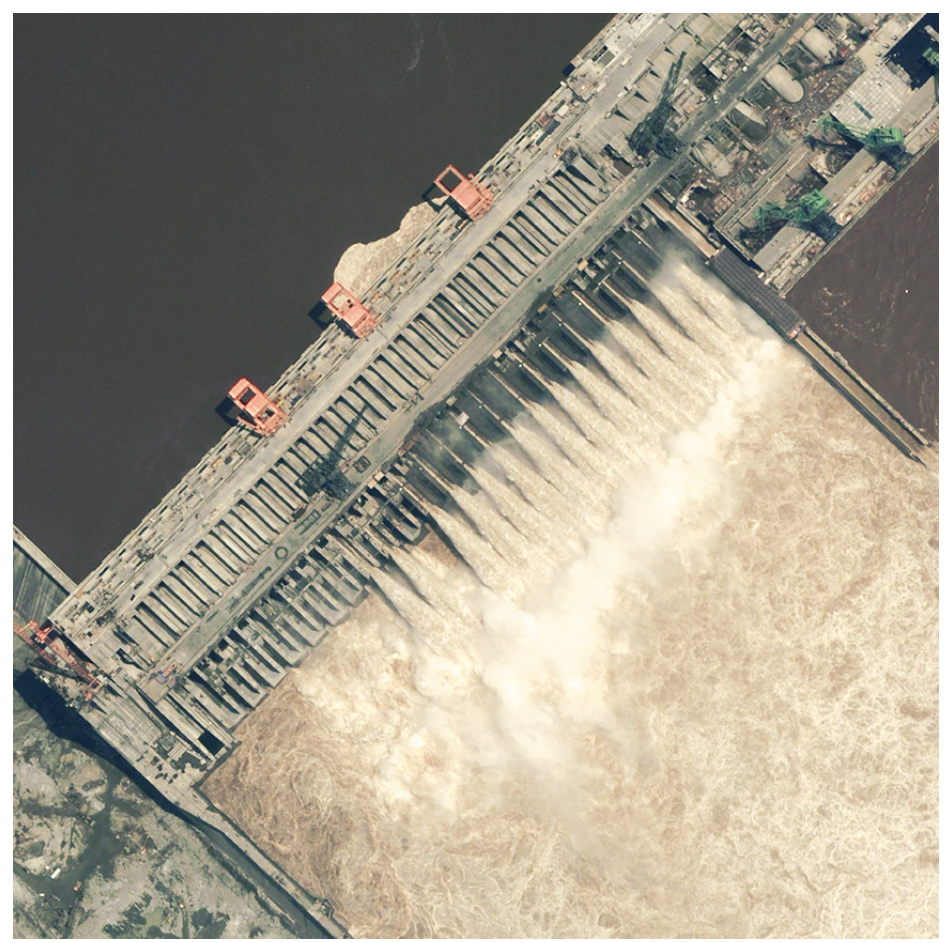

Figure 3. Top view of the flood control by the Three Gorges Dam.

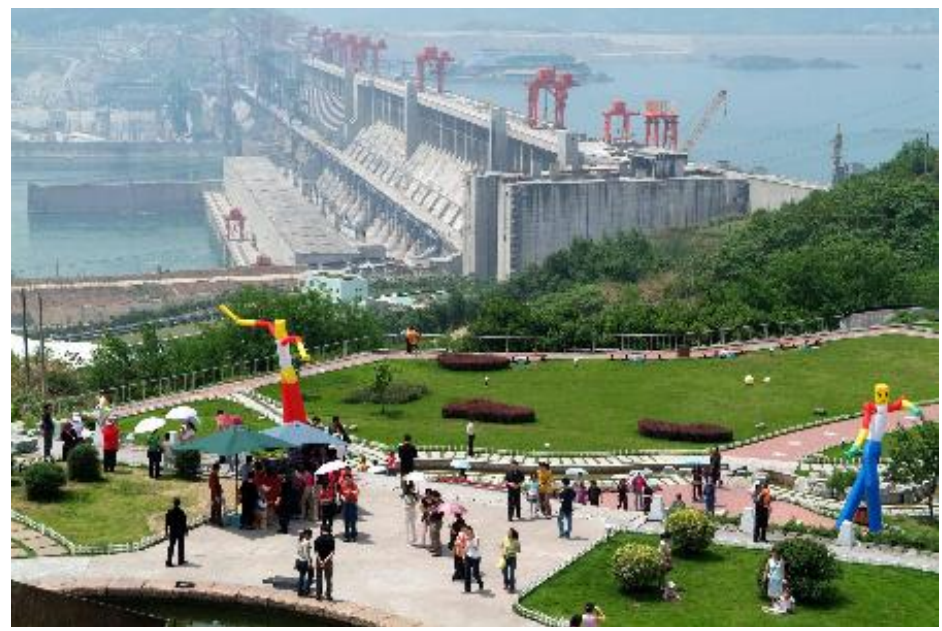

Figure 4. The Three Gorges Dam attracts travelers from around the world.

warmer climate to live through the winter. Most of the rare and endangered species of plants are distributed in the areas above 300 meters of the sea level, which is far above the maximum flood level [13]. Also, it is fortunate that only few rare and endangered animals inhabit areas that will be inundated by the reservoir. A study shows that the construction of the Three Gorges Dam will have no adverse effect on the living conditions of the Chinese dolphin and Yangtze alligator. In terms of water control, the reservoir will regulate water storage and discharge for navigation needs. Thus, downstream flow will be increased during the dry season, but without causing any change in the underground water level. Therefore, the swamp process of the valley will not be aggravated [4]. According to the design, the reservoir is expected to store water in October, which will result in reduced downstream flows. Note that in years of ordinary water flow, the river's flow is still higher than necessary to control the salt content in the Shanghai area. During periods of low water (i.e.: when sea water makes its most serious inroads), the increase in regulated flows by the dam will have the obvious effect of diluting salt 
water and reducing salt content. It is estimated that upon the completion of the Three Gorges Dam, the desalination process of the soil in the river's end and surrounding coastal areas will continue, and the water body will be more nutritious. It is also interesting to note that the Three Gorges Dam has been designed against earthquakes of magnitude as high as 7, which will protect the dam from damage of any natural earthquakes or quakes induced by the reservoir [10]. As a result, the Three Gorges Dam will act as the guardian for the protection and improvement of ecological environment of the Yangtze river.

\subsection{Environmental Purification}

Upon completion, the Three Gorges Dam will have an annual electricity output of 85 billion kWh, which is equivalent to a yearly saving of 50 million tons of coal, 14 thermal power plants with an installed capacity of 1.3 million $\mathrm{kW}$ each, and 3 coalfields with an annual output of 15 million tons. The Three Gorges Dam will allow China to avoid a large amount of waste water, waste gases and residues in addition to 120 million tons of carbon dioxide, 10,000 tons of carbon monoxide, 370,000 tons of compound oxygen and nitrogen per year [5]. The TGP is an excellent environmental purifier for China.

\subsection{Development-Oriented Resettlement}

From 1985 to 1993, the government has invested 1.2 billion yuan (US\$137 million) for resettlement of the population and cultural sites around the TGP areas. The total area affected by this resettlement amounts to approximately 14,000 hectares of land. Note that the resettlement included 30,000 inhabitants and some 100 historical sites [3]. In China, such resettlement is well-received by the affected population due to the fact that they will have the opportunity to free themselves from poverty. The amount of money that each relocated family can receive is approximately 30,000 yuan (US\$3500) based on the price level of 1993.

\subsection{Transfer of Water from Southern China to Northern China}

The annual runoff of the Yangtze river into the sea is 23 times more than that of the Yellow river. It is estimated that the total volume of water to be consumed from the Yangtze river after the year 2010 will be approximately 210 billion $\mathrm{m}^{3}$ per year, and about half of it can be recycled [9]. However in northern China, especially in Beijing, the shortage of water has greatly impaired the economic development. In the 1970's, Beijing suffered several severe water shortages. In 1981, the water crisis forced the thermal power plants to stop operation, which resulted in industry losses of about 2 billion yuan (US\$229 million), based on the price level of 1993. It is very common that high buildings have inadequate water supply. To alleviate this intense situation, Beijing has to get water supply from Guanting and Miyun reservoirs which were originally planned mainly for agriculture irrigation [7]. It is estimated that the amount of water shortage each year in Beijing, Zhengzhou, and several other northern cities after the year 2010 will total 40 billion $\mathrm{m}^{3}$. The rise to 175 meters of the Danjiangkou Dam, which is the source for transferring water from the southern to northern China, can only bring the water transfer volume up to 23 billion $\mathrm{m}^{3}$. Upon the completion of the Three Gorges Dam, by taking advantage of the time between 12:00 am to 6:00 am, when power transmission load is sharply released, the water level of the Three Gorges Dam will be raised by a dozen meters with water from Xiangxi river, enabling the water to run through Shenlongjia to the Danjiangkou reservoir and further through Henan, Hebei Province, to finally end in Beijing and Tianjin. As a result, the Three Gorges Dam can improve the water shortage in these areas [14]. The above facts show that transferring water from southern to northern China can relieve the water shortage problem in the northern region of China. Figure 5 shows a map of the path used to transfer water from southern to northern China.

\subsection{Water Supply and Irrigation}

The northern China plain makes up 40\% of the country's cultivated land, but its river runoff takes up only 6.5\% of the country's total. In the recent few decades, northern China has been developing very rapidly in industry, agriculture, business, trade, science and, tourism. All these, together with the population explosion, have made water crisis in these areas worse than ever. For instance, many rivers (such as Shaying river, Daqing river, and Ziya river) used to be very highly developed in navigation, but they are no longer suitable for navigation now. For water supply and irrigation, the limited underground water has been over extracted. Water is vital in northern 


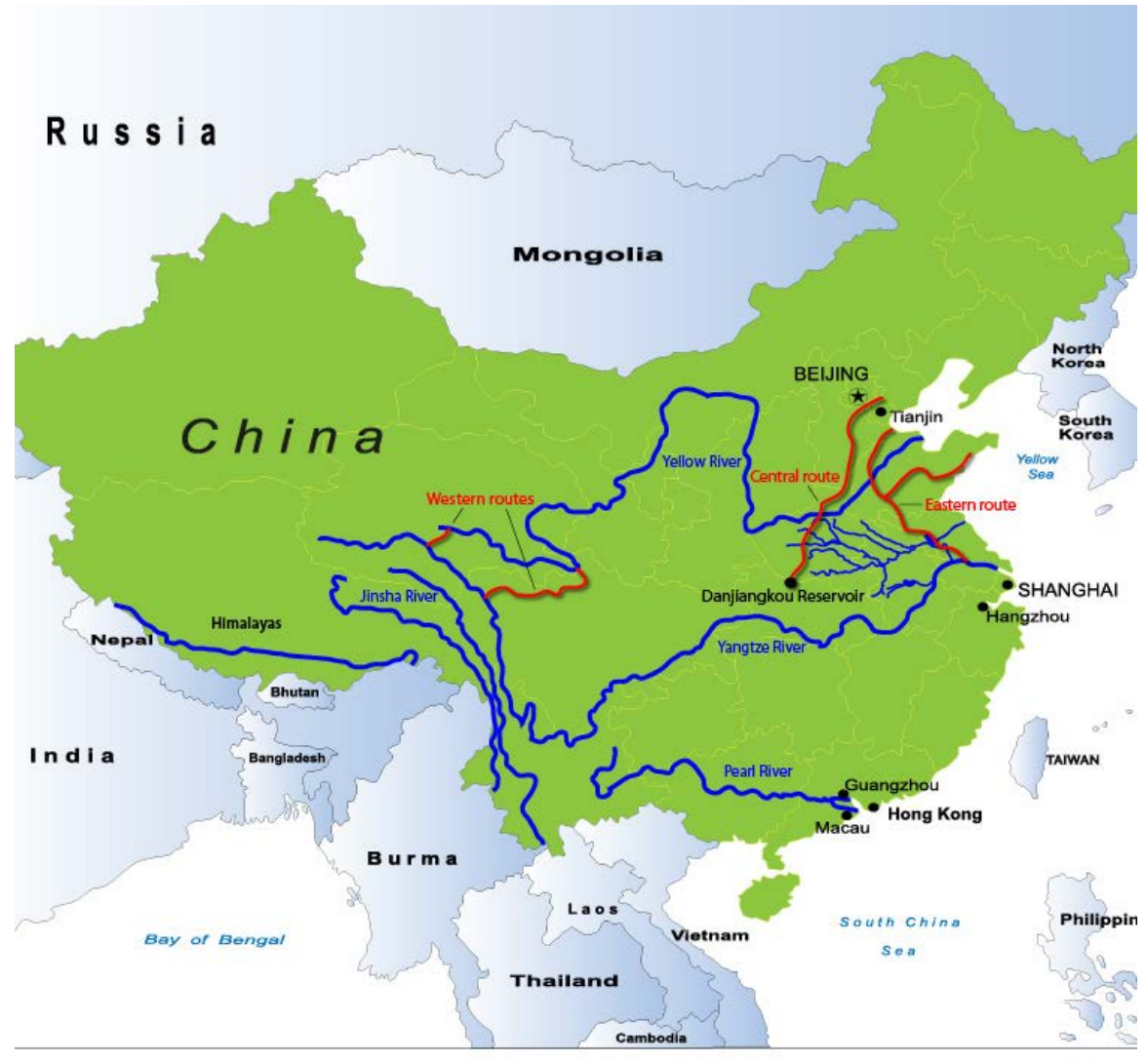

South-North Water Transfer Project, 2050

Figure 5. A map of the path used to transfer water from southern to northern China.

China areas because these are important production areas of grain and cotton in China. The estimated annual shortage of water in these areas is about 70 billion $\mathrm{m}^{3}$. The only and best way to overcome this problem is to construct the Three Gorges Dam. Further extension of the transferring canal from Beijing to the Han river will enable the water of the Yangtze river to flow up north. Thus, the once thirsty land can now become hydrated.

\section{The Four Main Drawbacks of the Three Gorges Dam}

Although as perfect as the Three Gorges Dam may seem to be, it has its own disadvantages as well. This section discusses the four main drawbacks of the Three Gorges Dam: environmental impact, effect on local culture and aesthetic values, and sedimentation.

\subsection{Environmental Impact}

It has been noted that the water quality in the higher banks of Yangtze is decreasing slowly, due to the dam's preventing dispersal of pollutants; algal blooms have risen gradually since the construction of the Three Gorges Dam. Also, soil erosion has increased, engendering riverbank collapses and landslides. Fortunately, the Chinese government has invested tens of billions of yuan in order to prevent pollution and geological disasters by various means, for instance, tree planting, measures to maintain biodiversity, shutting 1500 polluting industrial and mining enterprises, and building 70 sewage and waste treatment plants [15].

While logging in the area was required for construction which adds to erosion, stopping the periodic and uncontrolled flooding of the river will lessen bank erosion in the long run. Studies have shown that there is a reduced amount of silt transported by the Yangtze river to the Yangtze delta because there is a build up of silt in the reservoir [15]. However, this could reduce the electricity generation of the dam, and most importantly, it could result in erosion and sinking of coastal areas due to the lack of silt deposited in the peninsula. 


\subsection{Effect on Local Culture and Aesthetic Values}

The negative effects of the Three Gorges Dam on local culture and aesthetic values are mainly due to the 600 $\mathrm{km}$ (375 miles) long reservoir that will flood some 100 archaeological sites. In addition, the appearance of the Three Gorges will be altered as the water level rises over one hundred meters at various locations [16]. As of now, numerous cultural and historical relics have been relocated to higher ground as they are discovered. However, the flooding caused by the TGD will certainly cover some undiscovered relics. Also, several other sites could not be moved and will be flooded because of their location, size or design. One interesting example is the famous hanging coffins site high in the Shen Nong Gorge (Figure 6). The latter site contains bits and pieces of the homeland of the $\mathrm{Ba}$ (an ancient people who settled in the region more than 3000 years ago). The Ba had a tradition to bury the dead in coffins in caves high on the cliff. They believed that a dead body buried in the ground will turn the corpse into a vampire [17]. Unfortunately, such famous historical site will soon be submerged.

\subsection{Sedimentation}

Two major problems have been identified and associated with the Three Gorges Dam. The first problem is related to sedimentation, and the second problem is that the dam sits on a seismic fault. In fact, is has been studied that excessive sedimentation can block the sluice gates, which in turn can cause dam failure under some conditions. Estimations have been made and have revealed that the Yangtze river will add about 530 million tons of silt into the reservoir on average per year [8]. On a prolonged period of time, the latter silt is believed to accumulate behind the walls of the dam, and as a consequence, the silt will contribute to the blocking of the turbines' entranceway. In addition, the lack of silt down stream would contribute to other problems. For instance, hydrologists believe that the lack of silt would make downstream riverbanks more vulnerable to flooding. One of the major cities of China, Shanghai, located approximately $1600 \mathrm{~km}$ away from the Three Gorges Dam, is located on a massive plain of sediment. The city of Shanghai, more than one thousand miles (1600 km) away from the dam, rests on a massive plain of sediment. Usually, the silt strengthens the bed on which Shanghai is built. Due to the lack of silt caused by the construction of the dam, Shanghai will be more vulnerable to inundation [18]. Another problem with the dam is that it sits on a seismic fault, and this poses a great challenge to the engineers in designing the dam, which in turn must be able to withstand earthquakes of magnitude as high as 7.

\section{Conclusion}

The construction of the Three Gorges Dam is without doubt one of the largest technological achievements in the $21^{\text {st }}$ century. However, as with all technological implementations, there are advantages and disadvantages. On one

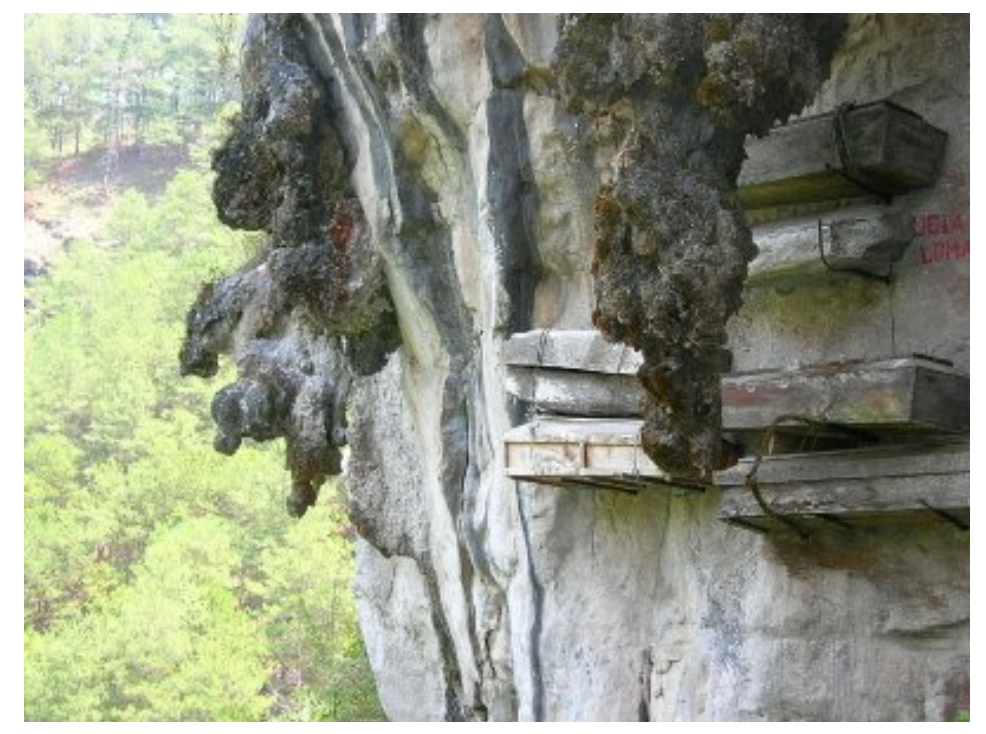

Figure 6. The famous hanging coffins site high in the Shen Nong Gorge. 
hand, the benefits of the Three Gorges Dam are flood control, power generation, navigation, aquaculture, tourism, ecological protection, environmental purification, development-oriented resettlement, transfer of water from southern China to northern China, and water supply and irrigation. On the other hand, the drawbacks of the dam are environmental impact, effect on local culture and aesthetic values, sedimentation, and national security concerns. In an environmental impact point of view, the Three Gorges Dam shows evidence that it has more advantages than disadvantages. Thus, by carefully balancing the pros and cons, one can say that the Three Gorges Dam is an environmentally feasible project.

\section{References}

[1] Qiu, Z.G., Wu, L.Z. and Du, J.P. (2000) Sanxia kuqu nongcun yimin anzhi moshi tantao (Exploring the Three Gorges Rural Resettlement Pattern). People's Yangtze River, 31, 1-3. (Cited in Heggelund 2007)

[2] Yardley, J. (2007) Chinese Dam Projects Criticized for Their Human Costs. The New York Times, 19 November 2007.

[3] Park, Y.-S., Chang, J., Lek, S., Cao, W. and Brosses, S. (2003) Conservation Strategies for Endemic Fish Species Threatened by the Three Gorges Dam. Conservation Biology, 17, 1748-1758. http://dx.doi.org/10.1111/j.1523-1739.2003.00430.x

[4] Yue, P. and Chen, Y. (1998) China Red Data Book of Endangered Animals: Pisces. Science Press, Beijing.

[5] Wu, L., Zhang, Q. and Jiang, Z. (2006) Three Gorges Dam Affects Regional Precipitation. Geophysical Research Letters, 33, Article ID: L13806. http://dx.doi.org/10.1029/2006GL026780

[6] Xu, K., Milliman, J.D., Yang, Z. and Wang, H. (2006) Yangtze Sediment Decline Partly from Three Gorges Dam. EOS, 87, 185-190.

[7] Xie, S., Li, Z., Liu, J., Xie, S., Wang, H. and Murphy, B.R. (2007) Fisheries of the Yangtze River Show Immediate Impacts of the Three Gorges Dam. Fisheries, 32, 343-344.

[8] World Commission on Dams (2000) Dams and Development. Earthscan Publishers, London, 448.

[9] Gleick, P.H. (1998) The Status of Large Dams: The End of an Era? In: Gleick, P.H., Ed., The World's Water 19981999: The Biennial Report on Freshwater Resources, Island Press, Washington DC, 69-104.

[10] Li, H., Waley, P. and Rees, P. (2001) Reservoir Resettlement in China: Past Experience and the Three Gorges Dam. The Geographical Journal, 167, 195-212. http://dx.doi.org/10.1111/1475-4959.00018

[11] Heggelund, G. (2007) Running into Dead Ends: Challenges in Researching the Three Gorges Dam. Woodrow Wilson International Center for Scholars, Washington DC. China Environment Series, 7, 79-83.

[12] McCully, P. (1996) Silenced Rivers: The Ecology and Politics of Large Dam. Zed Press, London.

[13] Oster, S. (2007) In China, New Risks Emerge at Giant Three Gorges Dam. The Wall Street Journal, 29 August 2007, 11.

[14] Stratton, A. (2007) World’s Largest Hydroelectric Dam Is Safe, Beijing Declares. The Guardian, 27 November 2007.

[15] Heggelund, G. (2004) Environment and Resettlement Politics in China: The Three Gorges Project. Ashgate Publishing, Hampshir.

[16] Heggelund, G. (2006) Resettlement Programmes and Environmental Capacity in the Three Gorges Dam Project. Development and Change, 37, 179-199. http://dx.doi.org/10.1111/j.0012-155X.2006.00474.X

[17] Tan, Y. and Yao, F. (2006) Three Gorges Project: Effects of Resettlement on the Environment in the Reservoir Area and Countermeasures. Population and Environment, 27, 351-371. http://dx.doi.org/10.1007/s11111-006-0027-0

[18] Yang, Z., Wang, H., Saito, Y., Milliman, J.D., Xu, K., Qiao, S. and Shi, G. (2006) Dam Impacts on the Changjiang (Yangtze) River Sediment Discharge to the Sea: The Past 55 Years and after the Three Gorges Dam. Water Resources Research, 42, Cite ID: W04407. 
Scientific Research Publishing (SCIRP) is one of the largest Open Access journal publishers. It is currently publishing more than 200 open access, online, peer-reviewed journals covering a wide range of academic disciplines. SCIRP serves the worldwide academic communities and contributes to the progress and application of science with its publication.

Other selected journals from SCIRP are listed as below. Submit your manuscript to us via either submit@scirp.org or Online Submission Portal.
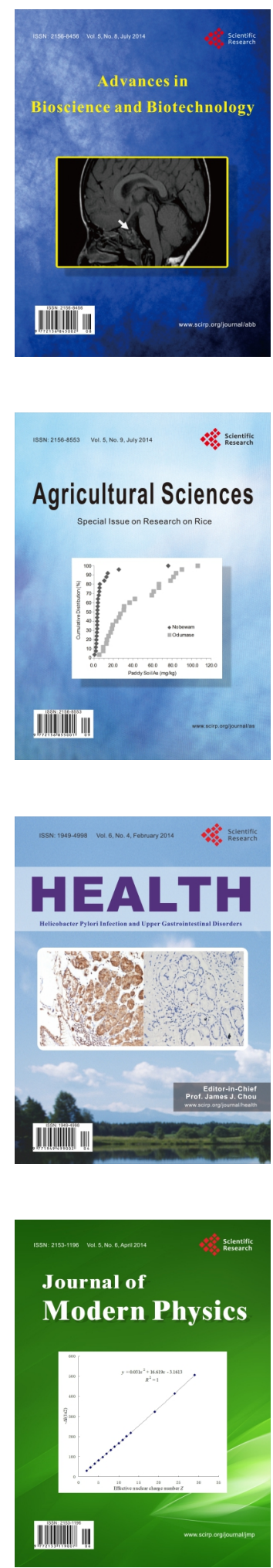
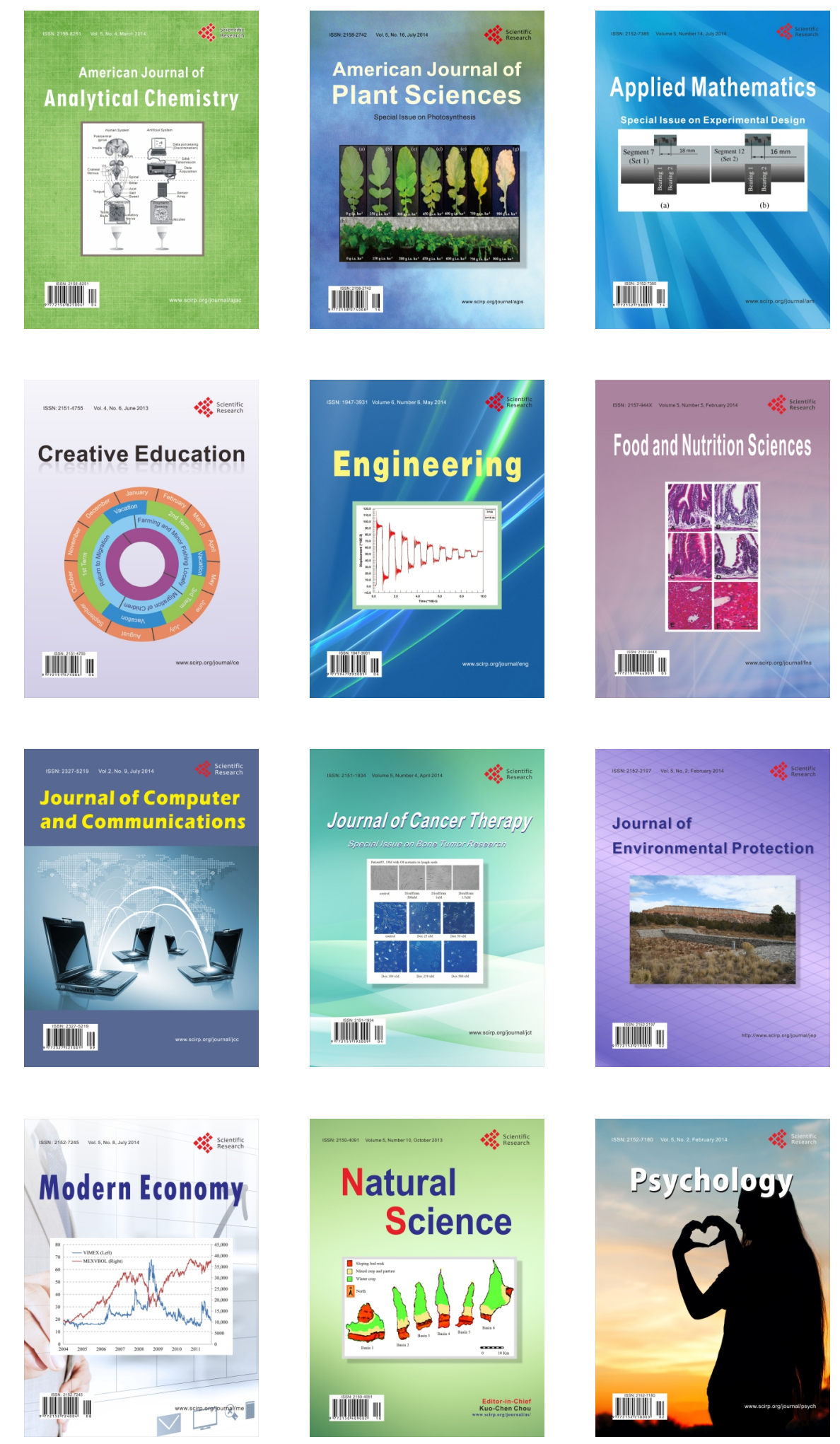